\title{
Not All Attitudes Are Propositional
}

\author{
Alex Grzankowski
}

\begin{abstract}
Most contemporary philosophical discussions of intentionality start and end with a treatment of the propositional attitudes. In fact, many theorists hold (tacitly if not explicitly) that all attitudes are propositional attitudes. Our folk-psychological ascriptions suggest, however, that there are non-propositional attitudes: I like Sally, my brother fears snakes, everyone loves my grandmother, and Rush Limbaugh hates Obama. I argue that things are as they appear: there are non-propositional attitudes. More specifically, I argue that there are attitudes that relate individuals to non-propositional objects and do so not in virtue of relating them to propositions. I reach this conclusion by not only showing that attempted analyses of apparently non-propositional attitudes in terms of the propositional fail, but that some non-propositional attitudes don't even supervene on propositional attitudes. If this is correct, then the common discussions of intentionality that address only propositional attitudes are incomplete and those who hold that all intentional states are propositional are mistaken.
\end{abstract}

No doubt, the flora and fauna of psychology have proliferated vastly, and surprising mental processes are postulated right and left. Nevertheless, at the heart of the picture, the fundamental explicandum, is the organism and its propositional attitudes: what it believes, what it learns, what it wants and fears, what it perceives to be the case.

Fodor (1975: 198)

\section{Propositionalism}

Philosophers have paid a great deal of attention to propositional attitudes. In fact, theorists interested in intentional states have focused almost exclusively on them, some even explicitly maintaining that all intentional states are propositional attitudes. This is unfortunate, for there are a class of intentional states that do not relate individuals to propositions, nor do they depend on relations to propositions. More specifically, there are attitudes that relate individuals to non-propositional objects and do so not in virtue of relating them to propositions. Examples include loving, liking, hating, and fearing, though there are likely many more. If this is correct, then the common discussions of intentionality that address only propositional attitudes are incomplete and those who hold that all intentional states are propositional are mistaken. 
Focusing on the propositional and neglecting the apparently non-propositional attitudes is indeed commonplace, but the neglect is the result of a number of distinct thoughts concerning intentionality and the attitudes. First, some theorists simply take the intentional and the propositional to be one and the same. For example, Daniel Stoljar offers the following:

In one formulation, the problem of intentionality is presented as concerning a particular class of properties, intentional properties. Intentional properties are those properties expressed by predicates formed from verbs of propositional attitudes. (Stoljar 1996: 161) In similar spirit, John Perry writes:

The phenomenon of intentionality suggests that attitudes are essentially relational in nature: they involve relations to the propositions at which they are directed. (Perry 1994: 387-8)

And along the same lines, some take it to be simply definitive of propositions themselves that they are the objects of the attitudes. For instance, McGrath (2007) writes, 'Propositions, we shall say, are the sharable objects of the attitudes and the primary bearers of truth and falsity.'

A second thought that has led to the neglect of the apparently non-propositional attitudes has it that the propositional attitudes are the most fundamental and all other intentionality reduces to them. Theorists who endorse such a thought do no define the apparently non-propositional attitudes away, but they treat them as merely derivative and not the central cases. For example, George Bealer $(1982 ; 1993)$ holds that whereas the apparently non-propositional states such as loving, fearing, and so on have 
'mediated intentionality', propositional attitudes are (metaphysically) the most fundamental intentional states. Intentionality, he says 'arises from propositional objects, i.e. from the thought to which a person stands in the relation of thought, belief, judgement, etc.' (1982: 225). Later, fleshing out the position more completely, Bealer argues that in order to (say) fear or like some object, one must stand in some appropriate propositional attitude relation to an appropriate proposition concerning the object (1993: 115). Accordingly, his discussion then focuses on propositional attitudes.

In a similar vein to Bealer, Mark Sainsbury (2010: 315) holds that '[t]hinking about an object reduces to a proposition-related activity'. (He takes 'thinking-about' to be a central case from which a more general position follows.) In support, he offers what appears to be a supervenience relation between the propositional and apparently nonpropositional attitudes:

To think about something is to entertain a suitably related internally singular propositional content. For example, for John to think about Pegasus is for John to stand in some attitudinative relation to a propositional content expressible using 'Pegasus.' The content might be that Pegasus flies, though no restriction is placed. The attitude might be that of believing or imagining or simply entertaining the proposition; again, there's no restriction. (Sainsbury 2010: 314)

Let us say that 'Propositionalism' is the metaphysical thesis (which will be explicated in greater detail below) that the most fundamental objects of the attitudes are propositions. As I am using the term, the above theorists are all propositionalists and are my primary targets. But as noted at the outset, my thesis has wider reach, for even 
amongst those who are open to the possibility of irreducibly non-propositional attitudes, there has been a strong preference for discussing only propositional attitudes. I wish to persuade such philosophers that not only is a careful treatment of the non-propositional attitudes in order but that a discussion of them in their own right is in order. For an example of the kind of philosopher I have in mind, one may look to Tyler Burge who, in his famous 'Individualism and the Mental', writes:

Our ordinary mentalistic discourse divides broadly into two sorts of idiom. One typically makes reference to mental states or events in terms of sentential expressions. The other does not. A clear case of the first kind of idiom is 'Alfred thinks that his friends' sofa is ugly.' A clear case of the second sort is 'Alfred is in pain.' Thoughts, beliefs, intentions, and so forth are typically specified in terms of subordinate sentential clauses, thatclauses, which may be judged true or false. Pains, feels, tickles, and so forth have no special semantical relation to sentences or to truth or falsity. There are intentional idioms that fall in the second category on this characterization, but that share important semantical features with expressions in the first - idioms like 'Al worships Buicks.' But I shall not sort these out here. I shall discuss only the former kind of mentalistic idiom. The extension of the discussion to the other intentional idioms will not be difficult. ${ }^{1}$ (Burge 1979: 74)

Burge isn't explicit about the metaphysical relationship between the propositional and the non-propositional, but it is clear that he is content to discuss only the propositional. John Searle provides another example. In his seminal book on intentionality, he writes: 
The hypothesis [...] is not that all or even many forms of Intentionality reduce to Bel and Des - that is plainly false - but rather that all Intentional states, even those which do not have a direction of fit and those which do not have a whole proposition as content, nonetheless contain a Bel or a Des or both, and that in many cases the Intentionality of the state is explained by the Bel or the Des. If that hypothesis is true then the analysis of Intentionality in terms of representation of conditions of satisfaction under certain aspects and with a certain direction of fit is very general in its application and not simply confined to the central cases. To the extent that the reader finds this hypothesis plausible, he will find it plausible that this book offers the beginnings of a general theory of Intentionality; to the extent that he finds it implausible the account will simply be a special theory dealing with the large number of central cases. (Searle 1983: 35) I, of course, take no issue with philosophers focusing their discussions, but for those (like Searle and Burge) who aren't resistant to the idea that there might be nonpropositional attitudes, I hope to make clear that it is time to bring them to the fore.

At this juncture one might reasonably wonder why Propositionalism has been adopted and why discussions have tended towards propositional attitudes, so it will be helpful to take a very brief look at a few motivations for the view. In fact, the motivations suggest that a tacit commitment to Propositionalism may indeed be widespread:

(i) Propositions, which stand in logical relations, allow us to properly index the mental states and their relations to one another. According to Lewis (1979), we may run the risk of losing this feature if the objects of the attitudes are varied. (ii) One might 
construct motivations for Propositionalism by arguing that without propositional relata practical syllogisms will be impossible to construct and a theory of motivation will flounder (though, of course, such a motivation rests on particular views about motivation and practical syllogism). ${ }^{2}$ (iii) One might also argue, in a similar vein to McDowell (1996) with respect to non-conceptual content, that if the attitudes are related in certain interesting epistemic ways (e.g. by the justification relation), then the contents of those attitudes must be both conceptual and propositional. ${ }^{3}$ (iv) Russellian accounts of quantified noun phrases, e.g. the $\mathrm{F}$, an $\mathrm{F}$, every $\mathrm{F}$, and so on, (at least on a naive view) ${ }^{4}$ require Propositionalism. Russell famously argued that quantified phrases such as the $F$ do not contribute denotations to propositions. Rather, they are incomplete symbols that combine with predicates and can be shown to involve first order quantification upon analysis. But if this is correct and if it is true that (say) Jones fears the Queen of England (where the quantified noun phrase takes narrow scope), a Russellian treatment will have it that Jones stands in a relation to an existentially quantified proposition to the effect that there is exactly one Queen of England.

Each of these motivations could be questioned, and they certainly aren't meant to be exhaustive, but for present purposes it is enough to see that the position has motivation and is connected with a range of important philosophical positions.

Before turning to our discussion, a few terminological clarifications are necessary. First, I take attitudes to be intentional mental states. A phenomenon (e.g. a state or an event) is intentional if (and only if) it is about something. ${ }^{5}$ For present purposes, we need only the sufficient condition, for I will focus on cases in which there is an object such that the phenomenon is about it and not on cases where an object is lacking, such 
as fearing Pegasus or liking unicorns. ${ }^{6}$ What it is for a state to be mental is a complicated matter, so rather than offer a definition, I will discuss clear cases such as fearing, loving, liking, and hating - mental states if any are. It is also important to be clear on our comparison class: propositional attitudes are just a special case of the intentional, mental states; that is, they are mental relations to propositions which in turn are about things such as ordinary objects and properties. In order to avoid confusion, let us say that the 'object' of a propositional attitude is a proposition. In general, we may identify the object of an attitude A by asking 'what is A-ed?'. It is important to notice that what the attitude is about or is directed upon may receive a different answer. For example, if I believe that grass is green, one may naturally say that what my belief is about is grass, but what I believe is that grass is green. To be a propositional attitude is to be an intentional mental state with a proposition for an object. If there are nonpropositional attitudes, they will be intentional mental states with objects that fail to be propositions. For instance, if a subject likes Sally, I will argue that the object of his attitude is not a proposition concerning Sally, nor does his standing in the liking relation to Sally depend upon a propositional attitude.

\section{Prima Facie Problem Cases for Propositionalism}

Why might one think that there are non-propositional attitudes? That is, why might one think that there are intentional, mental relations with non-propositional objects? The best way to answer this question is to look at the received motivations for thinking that there exist propositional attitudes. 
It has been persuasively argued by Fodor $(1975 ; 1983)$ and Dretske $(1991)$ that we should be propositional attitude realists on the grounds that folk-psychological explanations of action are both successful and indispensable. Our folk-psychological explanations often appeal to propositional attitude ascriptions such as belief and desire, and the best explanation of the effectiveness of the folk-theory is that there really are propositional attitudes answering to these ascriptions. If one is persuaded by this, it takes one as far as realism about the attitudes, but one might still be interested in their nature. One might, for example, be concerned over whether or not propositional attitudes are indeed relations to propositions. On this front, many theorists have looked again to our ascriptions for help, maintaining that they serve as a good guide to the metaphysical nature of the attitudes themselves. According to such theorists, there are a range of reasons for endorsing a relational view of propositional attitude ascriptions; that is, a view according to which propositional attitude ascriptions ascribe a relation between an individual and the semantic value of a that-clause; i.e. a proposition. ${ }^{7}$ Allow me to offer two especially persuasive ones. First, we are able to existentially generalize over propositional attitude ascriptions, as evidenced by the following intuitively valid inference:
A. John believes that grass is green.
B. So, there is something John believes.

A relational view allows one to makes light work of such inferences, claiming that the form is as follows:
$A^{\prime} . B(j, p)$.
$B^{\prime} . \exists x B(j, x)$. 
Second, it seems possible for distinct attitudes to be directed at the same thing. For example, Mary might believe that world peace is possible and John might hope that world peace is possible. A relational view allows one to explain truth of the claim that Mary believes what John hopes in terms of their relation to the same thing.

It is difficult to see how to make sense of the above points on a non-relational view. For example, if one were to maintain an alternative position according to which propositional attitude ascriptions predicate monadic properties of subjects (such as the property of believing-that-grass-is-green), an explanation of the truth concerning Mary and John and an explanation of the intuitive validities would be anything but forthcoming. One could certainly resist the relational position, but many (myself included) have found points like those just given very persuasive. So, if one is willing to grant that true sentences concerning our attitudes are a good guide to the attitudes themselves and if one agrees that attitude ascriptions are relational in form, one should conclude that the attitudes themselves are relational in nature. ${ }^{8}$ Since that-clauses very plausibly have propositions as their semantic values, we have a strong case for the view that attitudes such as belief are relations to propositions. For most theorists, none of this is controversial (in any event, I do not here wish to take issue with these points).

But suppose we follow the relational view of propositional attitudes and their ascriptions. What are we to make of ascriptions like the following, which take the form 'S V's y' (where ' $y$ ' is a non-that-clause noun phrase):

1. John fears cats.

2. Sally loves Bill.

3. Jones hates the color red. 


\section{Everyone likes chocolate.}

If one is satisfied with the above reasons for being a realist, relationalist about belief, desire, and so on, one should be just as satisfied taking fearing, liking, loving, and hating to be real relations. Ascriptions like those in 1-4 feature in successful folkpsychological explanations and predictions of behavior; e.g. all else equal, if a subject fears snakes and believes that there are snakes in the pit, he will intend to stay away from the pit. Furthermore, for reasons like those given above, the ascriptions are best understood relationally. If it is true that Sally fears snakes and Sam likes snakes, we are happy to say that Sally fears what Sam likes. And as before, we have intuitively valid inferences that are easily explained by a relational view:

D. Sally loves Nelson Mandela.

E. So, Sally loves something.

D. Sally loves Nelson Mandela.

F. So, there is something Sally loves (namely, Nelson Mandela).

And the similarities with states like belief and desire run deeper still, for fearing, liking, loving, hating, and so on certainly seem to be intentional. Not only are they intuitively about things, but they meet further marks of the intentional. Just as one might believe that Twain writes without believing that Clemens writes, one might fear Twain but not fear Clemens. The attitudes in question, much like belief, are capable of 'relating' one to things that don't exist - one can like Sherlock Holmes, fear Pegasus, and so on. (To reiterate, I don't here want to focus on such cases, but their intuitive truth gives one good reason for thinking the states are intentional, which is presently what is at issue.) But if we take the surface form of the above ascriptions to be (plus or minus a bit) their 
logical form, then by the same methodology to which we appealed in the case of belief, we should conclude that there are intentional relations which relate us to a range of non-propositional objects. ${ }^{9}$ Whereas in the case of belief, we found a that-clause, we now find terms and phrases with semantic values other than propositions. Of course, this is precisely where the propositionalist will enter the debate, arguing that despite appearances, the attitudes reported by 1-4 and their ilk either are propositional attitudes or are instantiated only because of them. Let us proceed, then, under the assumption that there is indeed a challenge for the propositionalist - she must account for the elements of folk-psychology that appear to commit us to attitudes with non-propositional objects. In what follows I will argue that there are cases in which propositionalists cannot meet the challenge.

\section{Varieties of Propositionalism}

Before considering whether or not propositionalists can handle the prima facie problem cases, we must must further clarify the position. Roughly, as noted at the outset, propositionalists maintain that the most fundamental objects of the attitudes are propositions. There are at least two forthcoming ways of precisifying this view (where the following are meant to be a priori, necessary truths):

Propositionalism A:

For every attitudinal relation between a subject and a non-propositional object, there is a propositional attitude or attitudes (of that subject's) in terms of which it can be analyzed.

Propositionalism B: 
For every attitudinal relation between a subject and a non-propositional object, there are propositional attitudes (of that subject's) upon which it supervenes. ${ }^{10}$

If Propositionalism A were true, then the most fundamental objects of the attitudes would indeed be propositions. According to Propositionalism A, what appear to be nonpropositional attitudes are, upon philosophical inspection, propositional attitudes. Propositionalism B is perhaps more tendentious and requires expansion. ${ }^{11}$

Propositionalism B is a weaker and more flexible position than Propositionalism A. According to it, when an individual is in a non-propositional, intentional relation at time the is in that relation in virtue of he himself being in some propositional, intentional relation at t. For example, suppose it is true that S loves y. Following Crane (2007), according to the propositionalist, what makes this true are certain propositional attitude facts of the lover. More generally, the propositionalist who adopts option B maintains that in order for S to $\mathrm{V} y, \mathrm{~S}$ must bear some or other propositional attitude relation to a proposition concerning y and bearing that relation is sufficient for his V-ing y. If true, the propositionalist has a good claim to the position that propositions are the fundamental objects of the attitudes. In slogan form (paying obvious homage to non-reductive physicalists), if Propositionalism B is true, 'the non-propositional attitudes are nothing over and above the propositional attitudes'.

Since there are a variety of supervenience relations, a bit more clarification is in order. On Propositionalism B, as indicated by the parenthetical 'of that subject's', the intended supervenience is local (rather than global). ${ }^{12}$ This is in light of the motivations for the view which, recall, rely on the explanation and prediction of behavior and/or an 
account of certain epistemic relations between intentional states. It is unclear how global intentional states would be immediately relevant to these questions (save for the usual externalist considerations). ${ }^{13}$ Additionally, the supervenience relation in question is intended to be asymmetric for the obvious reason that the propositionalist holds that the non-propositional depends on the propositional, i.e. one is only ever in a nonpropositional attitude in virtue of being in a propositional attitude state (or states).

\section{Against Propositionalism A}

On the face of things, there are non-propositional attitudes, but sometimes looks are deceiving. According to Propositionalism A, S V's y is to be analyzed as S V's that y is $F$, for some appropriate $F$.

Counterexamples to Propositionalism A are easy to come by. ${ }^{14}$ For the sake of concreteness, I'll focus on liking, though there is nothing special about the example. ${ }^{15}$

Suppose that Tom likes Sally. What shall we offer as an analysis of his attitude? If we demand some particular property, we will face immediate worries. For example, consider the following:

S likes Sally iff $S$ likes that Sally is nice.

But suppose that Tom is a masochist and doesn't like that Sally is nice. In fact, he takes that trait of Sally's to be a hurdle in their relationship. He may, nevertheless, like Sally. So we have a problem: the analysis just offered fails to provide a necessary condition. A person like Tom might like $y$ even if he fails to like that $y$ is nice.

One might have guessed that specificity to that degree was bound to fail, and in its stead the following seems far more attractive: 
$S$ likes $y$ iff $\exists F, S$ likes that $y$ is $F$.

But once again counterexamples are forthcoming: Obama likes that Osama is dead but Obama doesn't (and didn't) like Osama. Clearly, we have failed to offer a sufficient condition.

The proper fix appears to be something to which I gestured earlier: restrict quantification over F's in an 'appropriate' way. Unfortunately, not only is the restriction entirely unclear, but since people often have quite different preferences, perhaps even conflicting ones - both Tom and Jones might like Sally, and it might be true that Jones likes that she is nice and that Tom fails to like that she is nice - the propositionalist faces pressures on both ends. Anything with much specificity is bound to miss some cases, but anything broad is bound to overextend.

As an alternative, we might try to be specific in one sense while at the same time general in another:

$S$ likes $y$ iff $S$ likes that $y$ causes $S$ (himself) pleasure in some way or other.

But even this suggestion admits of counterexamples. One might like her dog even though the dog fails to cause any pleasure. The dog might in fact cause quite a lot of displeasure by tearing up the house. And against the other direction, I might like that the masseuse makes my back feel better without liking the masseuse.

Counterexamples abound, but problems can be shown to run deeper still. Beyond the pressure just offered, there are reasons for thinking that Propositionalism A is wrong-headed on the grounds of systematic misprediction. By aiming to capture, for example, liking in terms of liking-that we predict that what is liked is a state of affairs 
rather than, say, an individual. ${ }^{16}$ This fact is highlighted by the following. If John likes Sally (and Sally exists), then who John likes is Sally. But notice that for any propositionalist treatment of John's attitude, this entailment is unavailable. If John likes that Sally is pretty, it does not follow that who John likes is Sally. The same goes for any property that we might fill in. And this is not a special artifact of 'who'. If John likes Sally, then (so long as Sally exists) there is something he likes, namely Sally. But if John likes, say, that Sally is pretty, that entailment is again unavailable. There is, of course, something he likes when he likes that Sally is pretty, but it is that Sally is pretty. One may try other examples for herself, but change the property as you like and the problem of displacement remains. If Propositionalism A is adopted, what is intuitively V-ed is inappropriately displaced by a state of affairs involving the object in question.

Thus far, Propositionalism A looks both hopeless and problematic. One might, of course, try other attitudes on the right hand side such as belief or desire, or one might try combinations of attitudes. At this juncture, however, I think it is best to turn to Propositionalism B. If it fails, any version of Propositionalism A will fail as well.

Fortunately for the propositionalist, Propositionalism B promises to help on both fronts where Propositionalism A falls short. First, it is a far more flexible view that can perhaps avoid counterexamples. Second, it does not aim to analyze away the nonpropositional attitudes and so allows that in, say, liking Sally, Sally is the object of the attitude (though, of course, in a mediated way: it is only because the subject in question stands in an appropriate propositional attitude relation to a proposition concerning Sally). 


\section{Against Propositionalism B}

Propositionalism B is certainly more attractive than Propositionalism A, but it too faces difficulties. I will present two lines of pressure. They are intended to be taken independently, though given a certain dialectical stance, one might be comfortable with the second only in light of the first. If that is the case, the reader may take the first line as the primary line of attack.

First, I will argue that even with the flexibility afforded by turning to supervenience, the required sufficient conditions are often unavailable. Second, I will offer a counterexample to the propositionalist position - a case in which two individuals are intuitively described as identical with respect to their propositional attitudes, but are intuitively distinct with respect to their non-propositional attitudes. The case places a burden on the Propositionalist to produce the propositional attitude or attitudes that make the difference.

\section{Line 1}

Recall that according to the proponent of Propositionalism B, for any token instance of S V-ing y, there will be some or other propositional attitude or attitudes concerning $y$ which is true of $S$ and that propositional attitude will be sufficient for S's Ving y. I'm skeptical of the claim that propositional attitudes are necessary for being in non-propositional attitudes, ${ }^{17}$ but let us grant it: if S V's $y$, then S A's that $p$ (for some or other A and for some or other $\mathrm{p})$. The propositionalist has gained flexibility in what is allowable as a necessary condition in each token instance of S V's y, but once a necessary condition (or a range of them) in that instance makes the cut, it (or they) are 
then said to be sufficient for the token instance of S's V-ing y. Unfortunately, propositionalists cannot meet this sufficiency requirement.

An example will be helpful. Suppose that if Jones fears snakes there are some propositional attitudes or other that Jones must be in. But what propositional attitude or attitudes might be sufficient for his non-occurrent fear? Perhaps that Jones believes that snakes are dangerous? Jones, being an experienced snake charmer, might have that belief but not fear snakes. Perhaps that Jones believes that snakes are scary (to him)? After enough time with his therapist, Jones might come to believe that snakes are scary to him, but still not count as fearing snakes. When presented with a snake, Jones, let us suppose, wouldn't react, but when asked, he would freely assent to 'snakes are scary to me'. Perhaps combinations will help: Jones believes that snakes are scary to him, Jones wants to be far away from all snakes, and Jones fears that snakes will bite him. But all of this may be true and Jones might still fail to fear snakes. Jones might want to be away from them because he thinks they tend to explode (it's explosions that make him nervous, not snakes as such), the prospect of being bitten may sound bad to him on the grounds that he doesn't want fang marks on his skin before the big swimsuit competition, and, again, his belief may be explained by bad therapy. So, a person with the whole set of proposed propositional attitudes may not fear snakes.

Another example furthers the point. Suppose that if Jim likes Jackie this requires that Jim stand in some propositional attitude relation or other to some proposition or other concerning Jackie. But what propositional attitude will meet the requirement? One might suggest that Jim wouldn't like Jackie if he didn't think she existed, so perhaps believing that Jackie exists could serve as a first pass suggestion. But is this belief 
sufficient for Jim's liking of Jackie? Quite obviously it is not. But how might we do better? Jim believes that Jackie is nice? Jim likes that Jackie is kind? Let us just grant that both are true of Jim. Not only are they probably not necessary, but counterexamples to their sufficiency are still forthcoming. And combining the candidates doesn't seem to help: Jim believes that Jackie is kind, he hopes that she gets a good job, he likes that she helps the needy, but for all of that, he can't stand her. With just a bit of reflection, it strikes one that offering a sufficient condition in every case is anything but easy.

Propositionalists, even those who adopt Propositionalism B, have a hard row to hoe - for every non-propositional attitude the propositionalist must offer some or other sufficient propositional attitude (or attitudes). If a better candidate propositional attitude (or attitudes) is available than those just considered, it is now up to the propositionalist to offer it. Although there may be some cases in which being in certain propositional attitudes is sufficient for being in a non-propositional attitude, ${ }^{18}$ the outlook for the much stronger claim that this is always so is grim.

\section{Line 2}

In order to set up my case, I will first introduce an experiment that makes salient the possibility of a certain variety fearing: dispositional fear in the absence of any occurrent experiences of fear. The important point to be taken away from the experiment is that it is possible for a creature to be in a non-occurrent state of fear without ever having undergone an occurrent episode of fear (which might, for all I say, be a propositional attitude). ${ }^{19}$ Being innate is one way to accomplish this. 
Smith (1977) has constructed an experiment involving a species of bird known as the great kiskadee, which eats, among other things, small reptiles. Concomitant with the kiskadee is the micrurus, a highly venomous snake which displays a distinctive coralsnake pattern - a pattern composed of wide red, narrow yellow, wide black, and narrow yellow rings, in that order. If a kiskadee is bitten by a micrurus, death is likely.

In the experiment, six young kiskadees were raised in captivity and presented with wooden dowels painted in various ways. Some of the dowels were painted with rings of various colors and widths and others with stripes of various colors and widths. For instance, one set of dowels was painted with rings geometrically like that of the micrurus though colored differently. Other dowels covered similar options with striped patterns rather than rings. And, of course, one set of dowels was painted to resemble the micrurus as closely as possible. Young kiskadees were then presented with the various dowels and the number of pecks on each was recorded.

Importantly, the kiskasdees used in the experiment were taken from their nests just after their eyes were opened, and Smith points out that the natural nests are fully covered. Despite a general lack of worldly experience, the kiskadees exhibited behavior that suggests they have an innate fear of the micrurus. As Smith notes, the birds gave high intensity alarm calls to the coral-snake models, but not to other models.

With Smith's experiment in the background, a thought experiment involving creatures with a more robust cognitive life who are propositional-attitude-identical though distinct with respect to one of their intentional relations can be constructed.

Suppose that there are two ancient populations of creatures, A and B inhabiting distinct planets that are as similar as possible given the following. Population $\mathrm{A}$ has 
evolved in an environment in which a certain sort of snake claims many lives. Over the course of many generations, all the creatures have evolved such that upon the presentation of this type of snake they illicit fear responses - wide eyes, arched backs, gasping, running away, and so on. It is true of each member of the population that he or she fears snakes. In population $B$, on the other hand, there is no such threat and many normal members of that population don't react fearfully when presented with snakes.

Imagine that we remove a set of identical twins from each population and that they are raised from birth in identical environments. Let us call the twins from population A 'Aaron' and 'Adam' and the twins from population B 'Benson' and 'Barry'. All four of the creatures learn the same language and have qualitatively identical lives. Each of them is willing to openly and freely assent to 'snakes aren't dangerous' and each of them has expressed a desire to see a real snake. In fact, when they are told there are snakes nearby, they become excited and start to look for them and behave as one would who desires to see a snake. All four sincerely report the same desires, beliefs, intentions, wishes, hopes, and so on and all four behave in ways that suggest that they want the same things, believe the same things, and so on. But suppose that one day we present Aaron and Benson with the type of snake that is known to threaten tribe $A$ and find that Aaron, but not Benson, reacts fearfully. Despite their similarities, this seems possible (if not probable).

Intuitively, there is something it is like for Aaron in that situation and something it is like for Benson in that situation. According to many theorists, their experiences involve propositional attitudes, 20 so there are very likely a lot of propositional differences between Aaron and Benson during the time the snake is present. Or one might suggest 
that at the very moment the snake is presented, Aaron (causally or miraculously) comes to desire to be away from snakes. If desire is indeed a propositional attitude, then we would have a propositional difference. Let us grant all of this.

Turn now to Adam and Barry, neither of whom are presented with a snake at any time. They have undergone exactly the same experiences at every turn and both assent to the same sentences, express the same desires, and so on. It seems reasonable to conclude, given the known behavior of the two tribes and the experiment just run on Aaron and Benson, that Adam fears snakes but Barry does not. Much like a kiskadee that fears snakes before encountering any, Adam, but not Barry, sitting quietly in his room, fears snakes. Importantly, Adam and Barry seem to be propositionally identical they appear to want the same things and believe the same things, they have seen and heard the same things, and so on. All of our best evidence for the presence of propositional attitudes suggests that the creatures are propositionally the same. ${ }^{21}$ If there is an unreported or otherwise hidden propositional attitude that accounts for the difference between them, the burden is on the propositionalist to say what it is. ${ }^{22}$

There is nothing special about fear; similar thought experiments are available for other intentional relations as well - loving, hating, liking, and perhaps others. If this is correct, then there are some non-propositional attitudes that do not depend on propositional attitudes in the way suggested by the propositionalist.

Now, there is a dialectical delicacy to which I alluded at the beginning of this section. If one comes to the case just offered as a staunch propositionalist, one might reasonably take the case to show that there simply must be another propositional attitude lurking. Unless one is already committed to Propositionalism, I can't see why 
one would endorse this position. We are given folk-psychological ascriptions that play their usual role and which do not appear to ascribe relations to propositions, so I take it that the burden is on the propositionalist to offer up the attitude or attitudes. Further, in light of line 1, we have been given reason to think this won't always be possible. If, on the other hand, one comes to the case with an open mind concerning the truth of Propositionalism (and given the prima facie pressures against Propositionalism this seems to me the proper stance), the case should give one very good reason to reject Propositionalism B.

\section{Conclusion}

Given our folk-psychological practices of ascribing what appear to be nonpropositional attitudes, and given the failure of both Propositionalism A and B, we should conclude that there are attitudes which relate individuals to non-propositional objects and do so not in virtue of relating them to propositions. Fearing and liking are plausible examples. In philosophy, we also make use of relations such as being conscious of, attending to, knowing by acquaintance, seeing, and grasping (in Frege's sense), just to name a few. These relations are arguably intentional and they appear, at least on their face, to be non-propositional. The existence of non-propositional attitudes such as fearing and liking help pave the way for taking seriously the claim that other relations of great philosophical interest may also fail to be propositional. Of course, if all intentionality were, at bottom, propositional, our lives might seem easier for our theory of mind would be more parsimonious. But despite a desire for ease, theorists must take non-propositional attitudes seriously in their own right. Promising future work on intentionality lies in offering a positive account of these non-propositional attitudes. ${ }^{23}$ 


\section{Alex Grzankowski}

The University of Texas at Austin

Department of Philosophy

WAG 316, Mailcode C3500

Austin, TX 78712

alex.grzankowski@gmail.com 


\section{References}

Alston, W. P. (1998), Perception and Conception. New York: Fordham University Press.

Barwise, J. and R. Cooper (1981), 'Generalized Quantifiers and Natural Language’, Linguistics and Philosophy, 4(2): 159-219.

Bealer, G. (1982), Quality and Concept. New York: Oxford University Press.

---(1993), 'Materialism and the Logical Structure of Intentionality', in H. Robinson (ed.) Objections to Physicalism. Oxford: Clarendon.

Bennett, K. and B. McLaughlin. (2005). 'Supervenience', The Stanford Encyclopedia of Philosophy, Summer 2010. 2011, from <http://plato.stanford.edu/archives/ sum2010/entries/supervenience/>.

Block, N. (1996), 'Mental Paint and Mental Latex', Philosophical Issues, 7: 19-49.

Brewer, B. (2006), 'Perception and Content', European Journal of Philosophy 14(2): $165-181$.

Burge, T. (1979), 'Individualism and the Mental', Midwest Studies in Philosophy, 4(1): 73-121.

Byrne, A. (2001), 'Intentionalism Defended', The Philosophical Review, 110(2): 199-240.

Crane, T. (2001), Elements of Mind. Oxford: Oxford University Press.

D’Arms, J. and D. Jacobson (2003), 'The significance of recalcitrant emotion (or, antiquasijudgmentalism)', Royal Institute of Philosophy Supplement, 52(1): 127-145.

Davidson, D. (1963), 'Actions, Reasons, and Causes', The Journal of Philosophy, 60: $685-700$.

Dretske, F. (1991), Explaining Behavior: Reasons in a World of Causes. Cambridge: The MIT Press. 
---(1997), Naturalizing the Mind. Cambridge: The MIT Press.

---(2003), 'Experience as Representation', Philosophical Issues 13(1): 67-82.

Evans, G. (1982), The Varieties of Reference. New York: Oxford University Press.

Fodor, J. (1975), The Language of Thought. Cambridge: Harvard University Press.

---(1983), Representations: Philosophical Essays on the Foundations of Cognitive Science. Cambridge: The MIT Press.

Forbes, G. (2006). Attitude Problems: An Essay on Linguistic Intensionality. New York: Oxford University Press.

Heck, R. G. (2000), 'Nonconceptual Content and the "Space of Reasons"', The Philosophical Review, 109(4): 483-523.

Heck, R. G. (2007), 'Are There Different Kinds of Content?' in B. McLaughlin and J. Cohen (eds.) Contemporary Debates in Philosophy of Mind. Malden: Blackwell.

Larson, R. (2002), 'The Grammar of Intensionality', in G. Preyer and G. Peter (eds.) Logical Form and Language. Oxford: Clarendon Press.

Larson, R., M. den Dikken, et al. (1997), 'Intensional "Transitive" Verbs and Abstract Clausal Complementation', in P. Ludlow (ed.) Readings in the Philosophy of Language. Cambridge: The MIT Press.

Lewis, D. (1979), 'Attitudes De Dicto and De Se', The Philosophical Review, 88(4): 513-543.

Lycan, W. G. (1996), Consciousness and Experience. Cambridge: The MIT Press. McDowell, J. H. (1996), Mind and World. Cambridge: Harvard University Press. 
McGrath, M. (2007), 'Propositions', The Stanford Encyclopedia of Philosophy. Summer 2010. 2011, from <http://plato.stanford.edu/archives/fall2011/entries/propositions/ $>$.

Montague, M. (2007), 'Against Propositionalism', Noûs, 41(3): 503-518.

Partee, B. H. (1974), 'Opacity and Scope', in M. K. Munitz and P. K. Unger (eds.) Semantics and Philosophy. New York: University Press.

Pautz, A. (2009), 'What are the Contents of Experiences?', The Philosophical Quarterly, 59(236): 483-507.

---(2010), 'Why Explain Visual Experience in Terms of Content?', in B Nanay (ed.) Perceiving the World. New York: Oxford University Press.

Peacocke, C. (1983), Sense and Content. Oxford: Oxford University Press.

Perry, J. (1994), 'Intentionality', in S. Guttenplan (ed.) A Companion to the Philosophy of Mind. Oxford: Blackwell.

Priest, G. (2005), Towards Non-being: The Logic and Metaphysics of Intentionality. New York: Oxford University Press.

Prior, A. N. (1971), Objects of Thought. New York: Oxford University Press.

Quine, W. V. (1960), Word and Object. Cambridge: The MIT Press.

Routley, R. (1980), Exploring Meinong's Jungle and Beyond. Canberra: Research School of the Social Sciences.

Russel, B. (1905), 'On Denoting', Mind, 14(56): 479-493.

Sainsbury, R. (2008), 'Intensional Transitives and Presuppositions (Transitivos intensionales y presuposiciones)', Critica: Revista Hispanoamericana de Filosofìa: 129-139. 
---(2010). 'Intentionality without Exotica', in R. Jeshion (ed.) Singular Thought: New Essays. New York: Oxford University Press.

Salmon, N. (1998), 'Nonexistence', Noûs, 32(3): 277-319.

Schiffer, S. (2003), The Things We Mean. New York: Oxford University Press.

Searle, J. (1983), Intentionality: An Essay in the Philosophy of Mind. Cambridge: Cambridge University Press.

Shoemaker, S, (1990), 'Qualities and Qualia: What's in the Mind?', Philosophy and Phenomenological Research, 50: 109-131.

Siegel, S. (2010), 'Do visual experiences have contents?', in B. Nanay (ed.) Perceiving the World. New York: Oxford University Press.

Smith, S. M. (1977), 'Coral-snake Pattern Recognition and Stimulus Generalisation by Naive Great Kiskadees." Nature, 265: 535-563.

Speaks, J. (2005), 'Is There a Problem About Nonconceptual Content?', The Philosophical Review, 114(3): 359.

Stoljar, D. (1996), 'Nominalism and Intentionality', Noûs, 30(2): 221-241.

Szabo, Z. G. (2003), 'Believing in Things', Philosophy and Phenomenological Research, 66(3): 584-611.

---(2005), 'Sententialism and Berkeley's Master Argument', The Philosophical Quarterly, 55(220): 462-474.

Thau, M. (2002), Consciousness and Cognition. New York: Oxford University Press.

Thomasson, A. (2003), 'Speaking of Fictional Characters', Dialectica, 57(2): 205-223.

Travis, C. (2004), 'The Silence of The Senses', Mind, 113(449): 57.

Tye, M. (1995), Ten Problems of Consciousness. Cambridge: The MIT Press. 
---(2002), Consciousness, Color, and Content. Cambridge: The MIT Press.

Van Inwagen, P. (2003), 'Existence, Ontological Commitment, and Fictional Entities', in M. Loux and D. Zimmerman (eds). The Oxford Handbook of Metaphysics. Oxford: Oxford University Press. 
${ }^{1}$ Intentionalists about experience aim to break this divide by accounting for experiences wholly in terms of content. Intentionalists often couch their view in terms of propositional content. For instance, Byrne (2001) explicitly argues that perceptual experience is a propositional attitude. See fn. 20 below for additional sources related to this movement.

2 Traces of this type of line can be found in Davidson (1963) and in Lewis (1979).

3 See Heck (2000) and Speaks (2005) for helpful, recent discussions, though the literature on non-conceptual content is rapidly growing since its introduction by Evans (1982). In the existing literature, attention is focused on whether or not the objects of the relevant attitudes are conceptual or not. There seems to be little attention paid to whether or not they are propositional - that feature is generally taken for granted by both parties in the dispute. For a recent exception see Heck (2007) who entertains the possibility of pictorial content.

${ }^{4}$ Some contemporary proponents of a 'Russellian' theory of descriptions and quantifiers more generally adopt Russell's truth-conditions but give up the position that the phrases fail to denote. For example, a type theoretic semantics can assign semantic values to quantified noun phrases and could be used to avoid commitment to Propositionalism. See Barwise and Cooper (1981) for a helpful and important discussion of quantification in natural language.

${ }^{5}$ See Bealer (1993) for a detailed discussion of both the historical and contemporary uses of 'intentional'. He takes the contemporary definition to be the one offered in the main text (Bealer (1993), 104).

${ }^{6}$ There is no doubt that a full account of the attitudes must say something about the empty cases, for it seems possible to (say) fear things that don't exist. That is, it may not be the case that for every intentional phenomenon there is something such that the phenomenon is about it (though often the reasoning goes through). My focus will be on the cases in which it does go through.

Since (say) fearing Zeus is psychologically similar to fearing Obama, there is pressure to give a uniform account of the empty and non-empty cases. A full discussion deserves a paper-length treatment, though just to sketch some options, one might suggest that the objects of fearing, liking, and so on (in both empty and non-empty cases) aren't ordinary objects but are something like sub-propositional object-presentations (something akin to a concept, a sense, or a word-like representation in the language of thought). Alternatively, one might argue that fictional and mythical characters are real objects, but are abstract rather than concrete (see, for instance, Salmon (1998), Thomasson (2003), Van Inwagen (2003)) or are perhaps non-existent but real (this is famously the view of Meinong though contemporary advocates can be found in Priest (2005) and Routley (1980)). Such strategies preserve the relational nature, which is desirable given that states like fear are plausibly relations. See below in the main text for a defense of relationality. 
${ }^{7}$ For additional reasons and a fuller discussion of those offered, see Fodor (1983) and Schiffer (2003).

8 If one agrees that sentences of the form 'S A's that p' are true iff S A's that $p$, the move from language to metaphysics (though not irresistible) looks hard to deny. One could perhaps maintain that although the ascriptions are relational, the attitudes themselves are not. Robert Matthews (2007) has explored such a view, likening propositional attitude ascriptions to measure theoretic sentences.

9 Alternatively, one might stop short of a metaphysical discussion and argue, as 'Sententialists' do, that the best semantics for sentences like 1-4 reveal hidden sentential structure in the object position. Although such a view is plausible in a limited number of cases (e.g. 'to want' and 'to need'), the view lacks motivation in many other instances and often seems to get things wrong. The verbs in 1-4 are among the problem cases for Sententialists. For arguments against Sententialism, see Forbes (2006), Partee (1974), and Szabó (2003, 2005). For contemporary proponents of Senentialism, see Larson, et. al. (1997) and Larson (2002). An historical proponent can be found in Quine (1960).

10 There may be intermediary positions as well, though these two versions aim to carve out the upper and lower bounds of the view.

${ }^{11}$ As noted at the outset, Propositionalism B (or something very close to it) is held by Bealer (1982, 1993) and Sainsbury (2010). Crane (2001) and Montague (2007) both, on behalf of their opponents, mention the position but then claim that it is to give up Propositionalism. I disagree, as do some propositionalists (via conversation).

${ }^{12} \mathrm{~A}$ full discussion of supervenience would take us too far astray. See Bennett and McLaughlin (2005) for a detailed discussion.

13 That the non-propositional attitudes might globally supervene on the propositional attitudes would be an importantly distinct position. According to such a position, it would be impossible for two subjects in distinct worlds to differ in their non-propositional, intentional relations without there being some or other propositional attitude differences somewhere (or somewhen) in the worlds they inhabit. If such a position were established, there would be an interesting debate about whether the global supervenience of the non-propositional attitudes on the propositional attitudes is asymmetric. As far as I can tell, deciding on this last point would demand determining whether the most fundamental units of meaning are propositional or sub-propositional. Though interesting, the present debate is not that debate. At issue here is whether or not any attitudinal relations relate individuals to non-propositional objects and do so not in virtue of relating them to propositions.

14 Montague (2007) offers similar counterexamples against Propositionalism and I am indebted to her paper, though as noted above she fails to discuss Propositionalism B. 
15 There is, however, a question as to whether any seemingly non-propositional attitudes might be open to a propositionalist treatment of this sort. I suspect some are, but the present dialectic demands only that some aren't.

${ }^{16}$ See Forbes (2006) for a similar point concerning fear.

17 I admit that there is some intuitive draw. One might suggest, for example, that if one likes $\mathrm{y}$, surely there is something that one likes about $\mathrm{y}$ or that one believes about $\mathrm{y}$, or if one fears $y$ there must be something about $y$ that one fears or perhaps that one believes or desires. But the plausibility of this suggestion rests, I suspect, on a conflation between having a reason for an attitude and accounting (in a metaphysical sense) for that attitude. I might like Sally because I like that she is nice to me and I might fear Bill the bully because I fear that he is going to beat me up, but in both cases these are reasons for having an attitude and aren't obviously what my attitude consists in.

18 For instance, both Sainsbury (2010) and Prior (1971) suggest that in order to think about $y$, there is nothing more required than thinking that $y$ is $F$. This is indeed a tempting claim (though, interestingly, less temping, I think, for thinking-of).

19 Or at least involve propositional attitudes. D'Arms and Jacobson (2003), for instance, argue that at least some occurrent emotions are compound states constituted by both propositional attitudes and felt qualities. The issue of felt qualities seems to be beside the point when non-occurrent fear is at issue. One who non-occurrently fears, say, snakes may fear them even while comfortably asleep or in a coma.

20 Both intentionalists and 'qualia-freaks', for example, maintain that experiences have propositional content. Byrne (2001), Dretske (1997, 2003), Lycan (1996), Pautz (2009, 2010), Siegel (2010), Thau (2002), and Tye $(1995,2002)$ are representative of the intentionalist camp. Block (1996), Peacocke (1983), and Shoemaker (1990) are representative of the qulia-freak line. For general dissent, see Alston (1998), Brewer (2006), and Travis (2004).

${ }^{21}$ One might be tempted to look to the attitudes of the creatures' ancestors. Surely the ancestors of Adam and Barry are propositionally distinct and this distinction in part explains why Adam and Barry differ. But see the earlier discussion of local supervenience for reasons for thinking that pointing to the attitudes of individuals other than Adam and Barry is to miss the spirit of Propositionalism. 
22 It has been suggested to me that if Adam imagined that a snake is present, he might become afraid and that this might constitute the needed difference. First, this is not at all obvious, for one might imagine hitting a large ski jump or bungee jumping and not find himself at all scared while imagining, but then be stricken with fear when faced with the real opportunity. I myself have experienced this. Second, we may stipulate that none of the twins bother to do any imagining. For that matter, we could (without loss) say that they lack imaginative capacities altogether.

It has also been suggested to me that it is constitutive of fearing that one desire such and such, that one be away from what is feared, for example. Though it does seem unlikely that one would fear, say, snakes and not want to be away from them when presented with one (even if that desire were overridden by, say, the desire to conquer one's fear), constitution doesn't seem to be the right relation. It seems that it is because one fears snakes that one wants to be away from snakes. The fear of snakes causes one to want to be away from them. This is evidenced by the fact that when one asks why one wants to be away from snakes, 'I fear them' is a satisfactory answer. If fearing snakes was (at least partially) constituted by a desire to be away from them, this answer would be wholly unsatisfying. It would be similar to the unsatisfactory nature of Molière's 'explanation' of why the pill makes one sleepy in terms of it's dormitive virtue.

${ }^{23}$ Thank you to an anonymous referee for very helpful comments that led to substantial improvements. Many thanks are also due to the following friends and colleagues: Mark Sainsbury, Michael Tye, Josh Dever, Ray Buchanan, lan Proops, Adam Pautz, Hans Kamp, David Sosa, Steve James, Kate Ritchie, Reid Blackman, Alex Baia, Jeremy Evans, John Bengson, Brian Cutter, Neil Sinhababu, Ted Parent, and audience members at the 2010 Pacific APA. 